\title{
Effects of intra-dentate gyrus microinjection of myokine irisin on long-term potentiation in male rats
}

\author{
Efeitos da microinjeção da miocina irisina no giro denteado sobre a potenciação a longo \\ prazo em ratos machos
}

Saeed MOHAMMADI', Shahrbanoo ORYAN ${ }^{1,2}$, Alireza KOMAKI ${ }^{3}$, Akram EIDI', Mohammad ZARE/ ${ }^{3}$

\begin{abstract}
Induction of long-term potentiation (LTP) increases the storage capacity of synapses in the hippocampal dentate gyrus (DG). Irisin is a myokine generated from FNDC5 (a gene precursor) during exercise. Although intra-cornu ammonis 1 administration of irisin fortifies LTP in mice with Alzheimer's disease, the effects of intra-DG injection of irisin on the LTP in rats remains to be elucidated in vivo. In this study, male Wistar rats were randomly divided into a control group (saline), irisin (0.5, 1, and $1.5 \mu \mathrm{g} / \mathrm{rat}$ ), and dimethyl sulfoxide (DMSO). After treatment, the population spike (PS) amplitude and slope of excitatory postsynaptic potentials (EPSP) were measured in the DG of rats in vivo. Moreover, following completion of the experiments, the stimulating and recording sites in the hippocampus were confirmed histologically from brain sections. Furthermore, biochemical assays like malondialdehyde (MDA), total antioxidant capacity (TAC), and total oxidant status (TOS) were evaluated (the antioxidant markers were analyzed in the plasma). Our results suggest that all doses of irisin $(0.5,1,1.5 \mu \mathrm{g} / \mathrm{rat}) \mathrm{caused}$ an increase in the EPSP slope and PS amplitude when compared with the control group. In addition, the results obtained showed that irisin decreased TOS and MDA levels while increasing TAC levels as a marker of lipid peroxidation in plasma. The present report provides direct evidence that irisin affects the activity-dependent synaptic plasticity in the dentate gyrus.
\end{abstract}

Keywords: Dentate gyrus; neuronal plasticity; long-term potentiation.

\section{RESUMO}

A indução de potenciação de longo prazo (LTP) aumenta a capacidade de armazenamento das sinapses no giro denteado (DG) do hipocampo. A irisina é uma miocina gerada a partir do FNDC5 (um precursor genético) durante o exercício. Embora a administração intra-Cornu Ammonis1 de irisina fortaleça a LTP em camundongos com doença de Alzheimer, os efeitos da injeção intra-denteada de irisina sobre a LTP em ratos ainda precisam ser elucidados in vivo. Neste estudo, ratos Wistar machos foram divididos aleatoriamente em um grupo controle (solução salina), irisina (0,5, 1 e 1,5 $\mathrm{gg}$ / rato) e dimetilsulfóxido (DMSO). Após o tratamento, a amplitude do pico populacional (PS) e a variação dos potenciais pós-sinápticos excitatórios (EPSP) foram medidos no DG de ratos in vivo. Além disso, após a conclusão das experiências, os locais de estimulação e registro no hipocampo foram confirmados histologicamente a partir de secções do cérebro. Adicionalmente, ensaios bioquímicos como malondialdeído (MDA), capacidade antioxidante total (TAC) e status oxidante total (TOS) foram avaliados (os marcadores antioxidantes foram analisados no plasma). Nossos resultados sugerem que todas as doses de irisina (0,5, 1, 1,5 $\mathrm{\mu g} / \mathrm{rato}) \mathrm{causaram}$ um aumento na variação da EPSP e na amplitude da PS quando comparadas com o grupo controle. Além disso, os resultados obtidos mostraram que a irisina diminuiu os níveis de TOS e MDA, enquanto aumentou os níveis de TAC como um marcador da peroxidação lipídica no plasma. 0 presente estudo fornece evidências diretas de que a irisina afeta a plasticidade sináptica dependente de atividade no DG.

Palavras-chave: Giro denteado; plasticidade neuronal; potenciação de longa duração.

The hippocampus has long been considered important for learning and memory storage. It is generally believed that most information is stored in synapses in the form of modification in synaptic efficiency. In particular, two forms of synaptic plasticity, long-term potentiation (LTP) and longterm depression (LTD), have been broadly considered in the

${ }^{1}$ Department of Biology, Science and Research Branch, Islamic Azad University, Tehran, Iran

${ }^{2}$ Department of Biology, Faculty of Science, Kharazmy University, Tehran, Iran

${ }^{3}$ Neurophysiology Research Center, Hamadan University of Medical Sciences, Hamadan, Iran

Saeed Mohammadi iD https://orcid.org/0000-0001-6966-7493; Shahrbanoo Oryan (iD https://orcid.org/0000-0003-1930-2343;Alireza Komaki iD https://orcid.org/0000-0002-4161-4311;Akram Eidi (iD) https://orcid.org/0000-0002-6673-5347; Mohammad Zarei iD https://orcid.org/0000-0003-4034-3043 Correspondence: Alireza Komaki; Department of Physiology, School of Medicine, Hamadan University of Medical Sciences; Shahid Fahmideh Street, Hamadan, Iran; E-mail: Alirezakomaki1@gmail.com 
pursuit of understanding the molecular and cellular basis of learning and memory ${ }^{1}$. In a previous study, Farmer et al. showed that exercise produced enhanced neurogenesis and LTP in the dentate gyrus (DG) of adult male Sprague-Dawley rats in vitro ${ }^{2}$. Physical exercise improves mental health by improving cognitive function and memory in neurological and psychiatric disorders such as depression, epilepsy, stroke, and Parkinson's disease. However, the underlying molecular mechanisms explaining the benefit of exercise remain unknown ${ }^{3}$. Myokine is secreted from the muscle fibers during physical exercise. It has been reported that myokine may be transported to organs through the circulatory system, revealing a mechanism through which it could reach the central nervous system. Irisin, a myokine that is secreted in the form of a protein called fibronectin type III domain containing 5 (FNDC5), induces brain-derived neurotrophic factor (BDNF) expression in the brains of rats. Pigment epithelium-derived factor, growth differentiation factor 11, vascular endothelial growth factor $\mathrm{A}$, and fibroblast growth factor 21 have also been reported to be active in the nervous system ${ }^{4}$. Additionally, interleukin-6, a major compound of myokine, has been reported to play a critical role in the nervous system $^{5}$. This suggests that there is a connection between myokines and the nervous system.

Irisin, named after the Greek goddess Iris, is a novel and multifunctional therapeutic hormone-like myokine. This peptide (112 amino acid residue) is isolated from the FNDC5 gene $^{6}$. According to Wrann et al. ${ }^{7}$, expression of irisin affected by exercise increases in the hippocampus formation, particularly in the DG. It is now clear that irisin can increase levels of BDNF and other growth factors, stimulate neurogenesis and increase resistance to brain insult ${ }^{8}$. Irisin may prevent cognitive deficits in the rat brain that are due to oxidative stress. Oxidative stress not only refers to the imbalance between the cellular production of reactive oxygen species and the antioxidant mechanisms that remove them but is also responsible for neuronal damage and degeneration in brain disorders, including stroke, epilepsy, and Alzheimer's disease ${ }^{9}$. Emerging evidence has indicated that oxidative stress impairs memory-related synaptic plasticity ${ }^{10}$.

It is noteworthy that irisin, like BDNF, belongs to the myokines. The FNDC5/irisin stimulates the expression of BDNF in the hippocampus, a brain region centrally involved in learning and memory. This raises the possibility that FNDC5/irisin could play a neuroprotective role in brain ${ }^{11}$. Moreover, previous studies have shown that administration of BDNF not only reduced oxidative stress but also modulated the outcome of a saturated fat diet on synaptic plasticity and cognition in rats $^{12}$. In continuation of our previous studies about the beneficial effects of irisin on spatial and passive-avoidance learning and memory ${ }^{4}$, in the present investigation we evaluated the hypothesis that FNDC5/irisin could be a key mediator of the beneficial effects of exercise on synaptic plasticity in addition to the interplay between irisin and oxidative stress in male rats.

\section{METHODS}

\section{Animals}

A total of 50 male Wistar rats (aged 10-11 weeks) with a mean weight of $280 \pm 15 \mathrm{~g}$ (range, 255-300 g) were supplied by Hamadan University of Medical Sciences and kept in a 12:12 hour light/dark cycle with access to water and food ad libitum (with the exception of testing periods) at $22 \pm 2^{\circ} \mathrm{C}$. In a random manner, 10 rats were allocated to the dimethyl sulfoxide (DMSO), irisin (0.5, 1 , and $1.5 \mu \mathrm{g} / \mathrm{rat})$, and control groups. The University Ethics Committee approved all the procedures in this study (approval number: IR.UMSHA.REC.1396.231), which were consistent with the National Institutes of Health guidelines.

\section{Drugs prescription}

The DMSO, irisin/FNDC5 (human recombinant, purity by SDS-PAGE $\geq 95 \%$, mol wt $13 \mathrm{kDa}$ ), and urethane (ethyl carbamate) were purchased from Sigma-Aldrich Corporation (St. Louis, MO; USA). Irisin (0.5, 1 , and $1.5 \mu \mathrm{g} /$ rat) was dissolved in DMSO (the final DMSO concentration in the diluted working solution was $0.04 \%$ ) and micro-injected into the DG. In addition to the irisin groups, the rats received either saline or DMSO in other groups. All doses were chosen on the basis of a previous experiment report ${ }^{13}$.

\section{Surgical procedures, electrophysiological recordings, and LTP induction}

Following an intraperitoneal injection of urethane $(1.5 \mathrm{~g} / \mathrm{kg}$; $250 \mathrm{mg}$ urethane $/ 1 \mathrm{ml}$ sterile water; supplemental injection if necessary) for inducing anesthesia in rats, a stereotaxic apparatus was used for surgical procedures. Using a shielded heating pad, the body temperature of animals was kept at $37.0 \pm 0.2^{\circ} \mathrm{C}$ during surgery ${ }^{4}$. After exposing the skull, in the lateral perforant path (PP), a bipolar stimulation electrode (concentric; diameter $125 \mu \mathrm{m}$ ), which was Teflon-insulated except for the tips, was inserted based on the Paxinos and Watson Atlas ( $4.3 \mathrm{~mm}$ lateral to the midline, $8.1 \mathrm{~mm}$ posterior to the bregma, and $3.2 \mathrm{~mm}$ ventral below the skull surface) $)^{14}$. Moreover, by lowering a bipolar electrode into the DG region ( $3.8 \mathrm{~mm}$ posterior and $2.3 \mathrm{~mm}$ lateral to the bregma and midline, respectively), the maximum field excitatory postsynaptic potential (EPSP) was determined (2.7-3.2 mm ventral). Using electrophysiological response monitoring in the DG, optimal ventral placement was achieved after single-pulse stimulation of the $\mathrm{PP}^{15}$. By changing the stimulation intensity and measuring the average of five responses per intensity, we plotted an input/output response curve. For the following stimulations, we used a stimulus intensity that could trigger a field potential of 50\% of maximum response. After using single stimuli for at least half an hour, response monitoring was carried out; every 10 seconds a stimulus was presented. The field EPSP slopes were $20-80 \%$ of the peak amplitude.

The LTP induction was performed as soon as a stable response baseline was achieved for at least 20 minutes, 
based on the high-frequency stimulation protocol $(400 \mathrm{~Hz}$; 10-second inter-burst interval; 10 bursts of 20 stimuli; and $0.2 \mathrm{~ms}$ stimulus duration) at stimulus intensity, producing almost 50\% of maximum response for the PS amplitude and EPSP slope. For evaluating the synaptic response of neurons in the DG region, PS and EPSP were measured at 5, 30, and 60 minutes post-high-frequency stimulation. Within 10-second stimulus intervals, the average of 10 consecutive responses was measured at each time point.

The eTrace package (www.sciencebeam.com) was used to describe the stimulus features. In addition, a current isolator unit (model A365; World Precision Instruments) was employed before PP transfer. Next, the potential field response was filtered $(1 \mathrm{~Hz}-3 \mathrm{kHz})$ in the DG region after passing through a preamplifier for maintaining amplification (1000x; DAM 80, World Precision Instruments) (Figure 1).

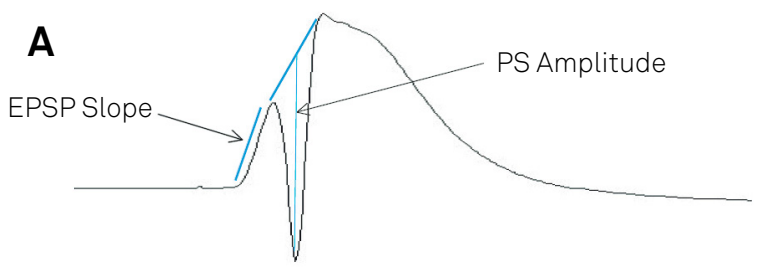

B
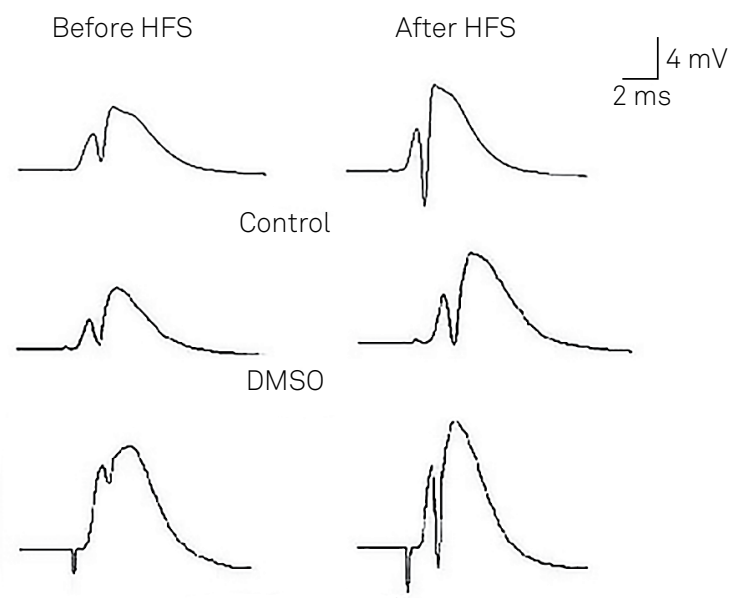

Irisin 0.5 microgram/rat
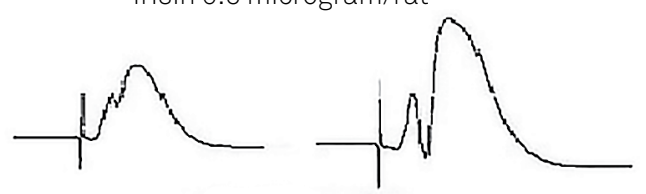

Irisin 1.0 microgram/rat
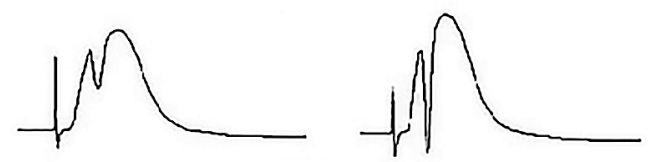

Irisin 1.5 microgram/rat

Figure 1. The excitatory postsynaptic potentials (EPSP) slope and population spike (PS) amplitude in the lateral perforant path-dentate gyrus (DG) synapses of the field potential sample traces in the control animal: (A) The arrows depict the PS and EPSP slope; (B) Stimulated field potential sample traces are shown in the DG region in the groups before and after high-frequency stimulation.

\section{Histology}

The recording and stimulating hippocampal sites were histologically confirmed after the experiments. Generally, the electrode location influences electrophysiological responses. The histological results were confirmed by electrophysiological findings, indicating the stimulating electrode location in the PP. The electrode location was confirmed independently. Finally, deep anesthesia was induced using urethane, and the animals were perfused with formal-saline $10 \%$ (the fixative solution, prepared by dissolving $8.5 \mathrm{~g}$ of sodium chloride in $900 \mathrm{ml}$ of distilled water and mixed with $100 \mathrm{ml}$ of $40 \%$ formaldehyde) through the heart. For the histological analysis, hematoxylin and eosin staining was applied for the coronal $50-\mu \mathrm{m}$ brain sections. A researcher blinded to the results of experiments confirmed the location of the electrode tip (Figure 2).

\section{Biochemical analysis}

At the end of the study, $5 \mathrm{~mL}$ of blood was taken from the right ventricle of the heart by cardiac puncture, transferred into heparinized tubes, and centrifuged at $3000 \mathrm{rpm}$ for 10 minutes at $4^{\circ} \mathrm{C}$. Plasma measurements were performed for malondialdehyde (MDA), total oxidant status (TOS), and total antioxidant capacity (TAC).

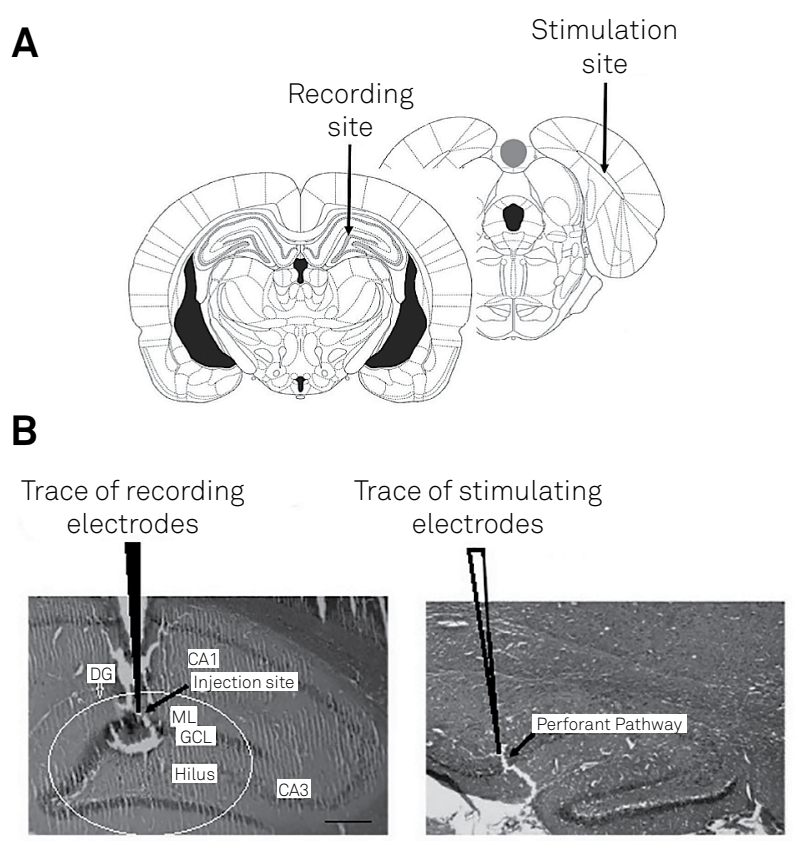

Figure 2. (A) A schematic drawing of the experimental design with stimulating electrode positioned in the perforant path and recording electrode positioned in the dentate gyrus. Paxinos and Watson, adapted ${ }^{14}$. (B) A photomicrograph illustrating the recording and stimulating electrode tip placement in a sagittal hippocampal segment. The recording electrode traces are on the left side, and stimulating electrode traces are on the right side. DG: dentate gyrus; CA1: cornu ammonis-1; CA3: cornu ammonis-3; ML: molecular layer; GCL: granular cell layer, scale bar: $0.5 \mathrm{~mm}$. 


\section{Evaluation of lipid peroxides}

To measure the serum levels of lipid peroxides, thiobarbituric acid reactive substance assay was used, based on a method described in the literature ${ }^{16}$. In this assay, after adding the serum or standard solution $(250 \mu \mathrm{L})$ to $20 \%$ trichloroacetic acid $(2.5 \mathrm{~mL})$, they were mixed with $0.67 \%$ thiobarbituric acid $(1 \mathrm{~mL})$. The mixture was heated for half an hour at $100^{\circ} \mathrm{C}$ and then placed on ice, followed by vigorous vortex mixing using n-butanol $(4 \mathrm{~mL})$. A spectrophotometer was used to determine the upper organic layer absorbance at $535 \mathrm{~nm}$ after centrifugation for 20 minutes at $3000 \times \mathrm{g}$; then, comparisons were made with a standard curve of 1,1,3,3-tetraethoxypropane.

\section{TAC measurement}

The ferric-reducing ability of plasma (FRAP) was evaluated for TAC measurements ${ }^{17}$. For this purpose, the FRAP reagent $(1.5 \mathrm{~mL}$; 10:1:1 ratio; $300 \mathrm{mmol} / \mathrm{L}$ of acetate buffer, $10 \mathrm{mmol} / \mathrm{L}$ of 4,6-tripyridyl-S-triazine in $40 \mathrm{mmol} / \mathrm{L}$ of $\mathrm{HCl}$, and $20 \mathrm{mmol} / \mathrm{L}$ of $\mathrm{FeCl}_{3}$ at $37^{\circ} \mathrm{C}$ ) was mixed with $50 \mu \mathrm{L}$ of the standard and test samples and then vortexed; absorbance was evaluated at $593 \mathrm{~nm}$. The blank was considered as the reagent without the added standard or sample. The assay was carried out in a 0-4 minute reaction time window at $37^{\circ} \mathrm{C}$.

\section{TOS measurement}

For the measurement of serum TOS, we used a method from the literature ${ }^{18}$. For this purpose, the samples $(35 \mu \mathrm{L})$ were mixed with reagent $1(225 \mu \mathrm{L})$, including $140 \mathrm{mM}$ of $\mathrm{NaCl}, 1.35 \mathrm{M}$ glycerol, and $150 \mu \mathrm{M}$ of xylenol orange in $25 \mathrm{mM}$ $\mathrm{H}_{2} \mathrm{SO}_{4}$ solution. A spectrophotometer was used to measure absorbance as a sample blank at $560 \mathrm{~nm}$. Incubation was performed for three to four minutes after adding $11 \mu \mathrm{L}$ of reagent 2 , consisting of o-Dianisidine and ferrous ion (10 and
$5 \mathrm{mM}$, respectively) in $25 \mathrm{mM} \mathrm{H}_{2} \mathrm{SO}_{4}$ solution. Finally, absorbance at $560 \mathrm{~nm}$ was recorded. Data are presented as $\mu \mathrm{mol}$ $\mathrm{H}_{2} \mathrm{O}_{2}$ equivalent/L. The detection limit, which is the mean level of TOS in the zero calibrator plus three standard deviations, was measured to be $1.13 \mu \mathrm{mol} \mathrm{H}_{2} \mathrm{O}_{2}$ equivalent/L after repeated evaluation of the zero calibrator (10 times).

\section{Data analysis}

For data analysis, two-way ANOVA and Tukey's tests were performed in SPSS version 16 (SPSS Inc, USA) at a significance level of 0.05 .

\section{RESULTS}

\section{Effects of irisin on EPSP slope and PS}

After PP stimulation, the recordings of field potential were collected for granular cells in the DG region. The LTP induction was achieved through high-frequency stimulation of PP. Figure 3 indicates the impact of irisin on the LTP of EPSP slope, in addition to the PS amplitude. The groups were significantly different regarding the EPSP slope [F (4.40) $=11.25, \mathrm{p}<0.001]$. The EPSP slope changed significantly $(\mathrm{p}<0.001)$ between the control and high-dose irisin $(1.5 \mu \mathrm{g} / \mathrm{rat})$ groups. Moreover, the EPSP slope was significantly different $(\mathrm{p}<0.01)$ between the controls and the group receiving $1 \mu \mathrm{g} / \mathrm{rat}$ of irisin. Similarly, the control rats and the rats receiving $0.5 \mu \mathrm{g}$ of irisin showed significant differences $(\mathrm{p}<0.05)$ (Figure 3$)$.

In addition, these groups were significantly different in the PS amplitude [F $(4.40)=42.39, \mathrm{p}<0.001]$, whereas the control and DMSO groups showed no significant difference ( $p>0.05)$. The findings revealed that the irisin groups $(0.5,1$, and $1.5 \mu \mathrm{g} / \mathrm{rat}$ ) were significantly different from the control group in terms of PS amplitude ( $p<0.05, \mathrm{p}<0.05, \mathrm{p}<0.001$, respectively) (Figure 4).

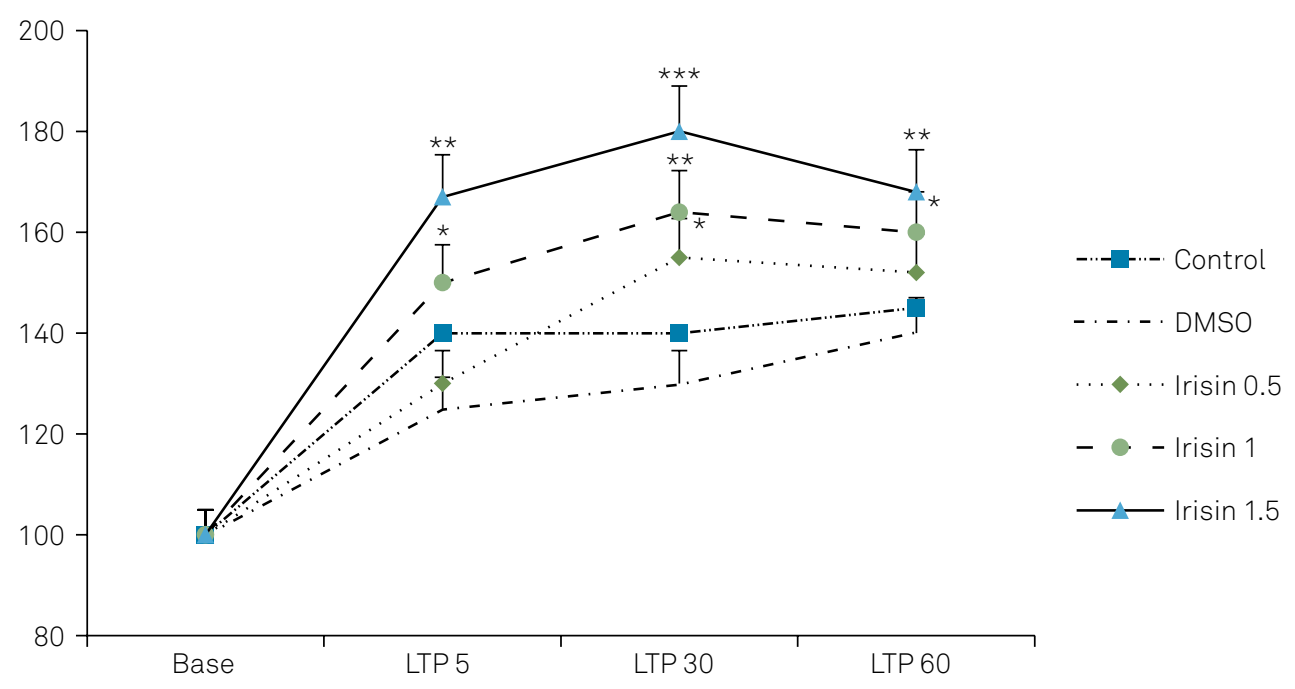

Figure 3. The effect of irisin on long-term potentiation (LTP) induction after perforant path stimulation. The groups showed a significant difference regarding the LTP of the excitatory postsynaptic potential slope in cell synapses. Values are expressed as the mean percentage of baseline $\left( \pm\right.$ SEM). ${ }^{*} p<0.05, * * p<0.01, * * * p<0.001$ vs. controls. 


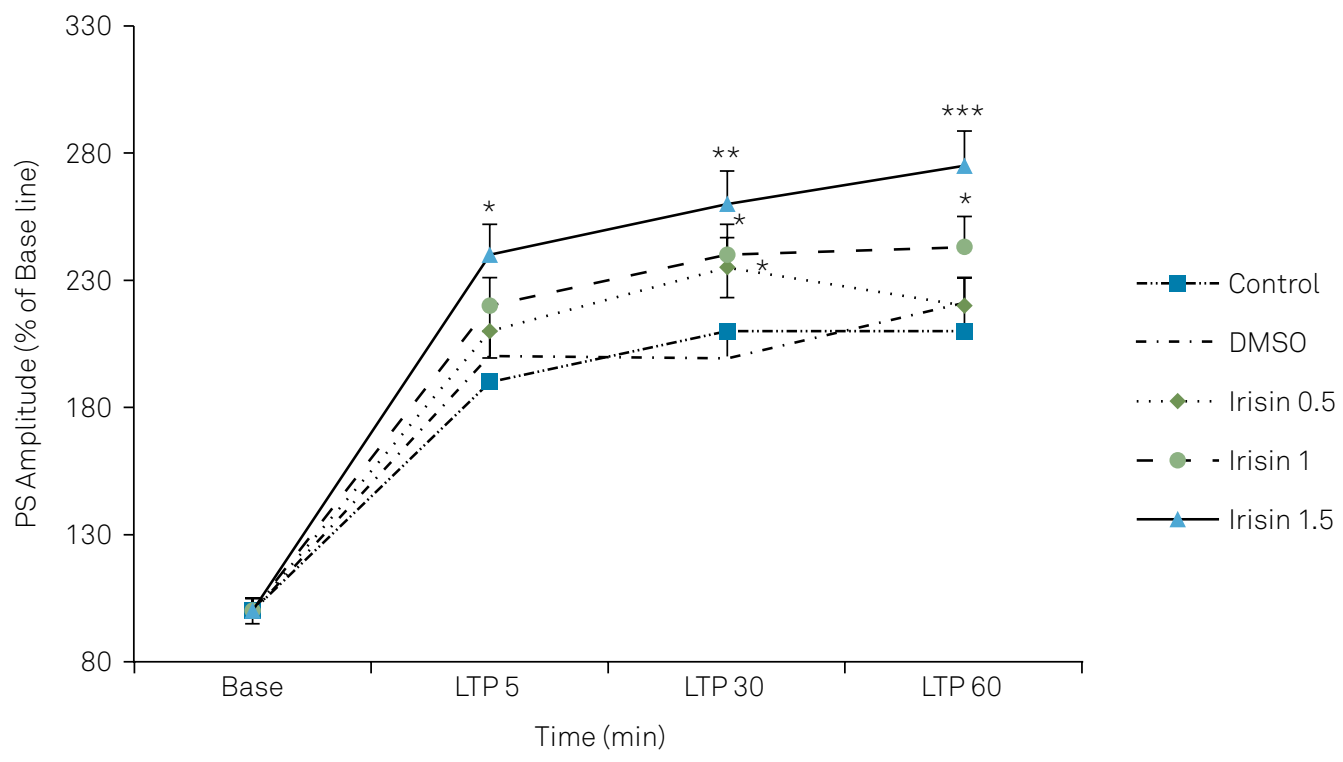

Figure 4. Time-dependent changes after irisin treatment in response to perforant path stimulation. Regarding the long-term potentiation (LTP) of population spike (PS) amplitude, the groups were significantly different. Values are presented as mean percentage of baseline \pm standard error of the mean (SEM). ANOVA and Tukey's test were applied for comparisons (*p $<0.05$, $* * \mathrm{p}<0.01,{ }^{* *} \mathrm{p}<0.001$ vs. controls).

\section{Effects of irisin on TOS, TAC, and MDA}

In the medium-dose $(1 \mu \mathrm{g} / \mathrm{rat} ; \mathrm{p}<0.01)$ and high-dose $(1.5 \mu \mathrm{g} / \mathrm{rat} ; \mathrm{p}<0.01)$ irisin groups, a lower TOS and a higher TAC were recorded compared with controls. In addition, groups receiving medium $(1 \mu \mathrm{g} / \mathrm{rat} ; \mathrm{p}<0.05)$ and high irisin doses $(1.5 \mu \mathrm{g} / \mathrm{rat} ; \mathrm{p}<0.01)$ were significantly different from the controls in the MDA level. The Table shows the serum levels of TAC, TOS, and MDA in the groups.

\section{DISCUSSION}

An important finding from this study was that irisin produced a significant increase in the ability to induce LTP in the DG in addition to decreasing levels of oxidative biomarkers in adult male rats.

An earlier research showed that irisin administration in Alzheimer's mouse models can rescue synaptic plasticity and new object recognition memory. Furthermore, Lourenco et al. have shown that bilateral intrahippocampal infusion of recombinant irisin (75 pmol per site) prevented amyloid- $\beta$ oligomer-induced impairment in new object recognition and fear conditioning memory ${ }^{19}$.
In agreement with these prior works, we found that direct intra-dentate gyrus administration of irisin reinforced both PS amplitudes and EPSP slopes in male rats; however, there were some differences between current studies compared with the previous study by Lourenco et al. ${ }^{19}$. In the present study, irisin was directly micro-injected into the DG of Wistar rats but, in the research by Lourenco et al., irisin was administered into the cornu ammonis-type 1 (CA1) slices from mouse models of Alzheimer's disease.

These findings show that irisin administration can directly fortify LTP in dentate gyrus as well as the hippocampus CA1 area. Also, in the present work, irisin increased the EPSP slope at 5, 30, and 60 minutes but, in the prior research, the EPSP slope was increased only at 120 minutes after intraCA1 injection of irisin. The EPSP slopes time differences between the present study and prior research may be clear evidence that irisin, when micro-injected directly into the dentate gyrus, can enhance LTP better than intra-CA1 injection. Another interesting study showed that micro-injection of BDNF (a myokine) mediated LTP (the EPSP slope intensified at 30 minutes after a single stimulus) in mouse ${ }^{20}$, which is in line with the current study; however, the latter study administered BDNF intracerebroventricularly in female

Table. Plasma parameters of total antioxidant capacity (TAC), malondialdehyde (MDA), and total oxidant status (TOS) of rats; TAC ( $\mathrm{mmol}$ Trolox equivalent/L), MDA ( $\mathrm{nmol} / \mathrm{mL}$ ), and TOS ( $\mu \mathrm{mol} \mathrm{H} 2 \mathrm{O} 2$ equivalent/L). Data are expressed as mean \pm standard error of the mean (SEM). $n=8$ per group.

\begin{tabular}{lcccc}
\hline Variable & Control & Irisin $(0.5 \mathrm{mg} / \mathrm{rat})$ & Irisin $(1 \mathrm{mg} / \mathrm{rat})$ & Irisin $(1.5 \mathrm{mg} / \mathrm{rat})$ \\
\hline MDA & $0.0543 \pm 0.0231$ & $0.0631 \pm 0.0022$ & $0.03019 \pm 0.0071^{\star}$ & $0.01717 \pm 0.0011^{\star *}$ \\
TAC & $0.2122 \pm 0.0126$ & $0.2244 \pm 0.0046$ & $0.4732 \pm 0.0025^{\star *}$ & $0.6333 \pm 0.0037^{\star *}$ \\
TOS & $1.315 \pm 0.0451$ & $1.1331 \pm 0.0040$ & $0.546 \pm 0.0678^{\star *}$ & $0.452 \pm 0.0419^{\star \star}$ \\
\hline
\end{tabular}


rats. Gulyaeva et al..$^{21}$ showed that inhibition of cathepsin-B/ myokine considerably reduced or fully blocked LTP in the CA1 region and was, therefore, essential for LTP, as well as enhancing expression of BDNF in adult hippocampal progenitor cells in mice ${ }^{21}$. In this investigation, although cathepsin$\mathrm{B}$ increased the EPSP slope at 30 minutes, at 60 minutes the EPSP slope decreased, which contrasts with our study outcomes because after microinjection of irisin, the EPSP slope at every moment (5-60 minutes) increased.

Irisin is discarded after physical action and released into the bloodstream ${ }^{22}$. Wrann et al. ${ }^{7}$, showed that exercise training raised FNDC5 in the hippocampus of mouse. Moreover, in their study, it was well established that the precursor for irisin, FNDC5, crossed the blood-brain barrier where it could be transformed into irisin ${ }^{7}$. Interestingly, FNDC5 was recently shown to mediate beneficial central nervous system effects of exercise training by up-regulating BDNF concentrations in special areas of the hippocampus, such as the $\mathrm{DG}^{7}$. As stated earlier, BDNF plays an important role in synaptic plasticity. In addition, BDNF has engaged as a target gene of cyclic $\mathrm{AMP}$ response element binding protein (CREB) and may be involved in exercise-induced neurogenesis in the DG. The $\mathrm{N}$-methyl-D-aspartate receptor may also be involved in this signal transduction pathway because its activation has been found to regulate CREB phosphorylation ${ }^{23}$ Consistently, irisin can enhance synaptic connections and neuronal developments in the hippocampus by affecting the BDNF system ${ }^{24}$.

Lourenco et al. ${ }^{19}$, also found that recombinant irisin in similar mechanisms stimulated the cAMP-protein kinase A (PKA)-CREB pathway in human cortical slices, a pathway that plays important roles in memory formation and has been found to be impaired in Alzheimer's disease models. Irisin-induced CREB phosphorylation was suppressed by PKA inhibition with myristoylated protein kinase inhibitor 14-22, a selective PKA inhibitor. They also found that PKA activity mediated protection against nuclear translocation of activating transcription factor 4 induced by amyloid- $\beta$ oligomers. Irisin further induced transient phosphorylation of extracellular signal-regulated kinase in cultured neurons ${ }^{19}$.

Brain is susceptible to oxidative harm because of the comparatively low concentrations of both enzymatic and nonenzymatic antioxidant systems and enormous amounts of free radical production due to high demand for oxygen ${ }^{25}$. Therefore, oxidative damage caused by free radicals also plays a key role in the cognitive decline and $\mathrm{LTP}^{26}$. Additionally, assessment of oxidative stress markers in both blood ${ }^{27,28}$ and brain $^{29}$ samples may assist in monitoring the connections between the LTP and oxidative stress ${ }^{30}$ and the possible impact of irisin on this relationship.

Malondialdehyde is a lipid peroxidation product and its concentration is proportional to the magnitude of the reactive oxygen radical-induced membrane damage. Lower MDA concentrations, therefore, suggest a reduction in free radical production ${ }^{31}$. In the present study, the irisin decreased the TOS and MDA levels while it increased TAC levels as a marker of lipid peroxidation in plasma.

Researchers have stated that irisin treatment prevents oxidative damage in brain tissue in a dose-dependent manner 9 . In the above-mentioned studies, MDA, glutathione peroxidase, and superoxide dismutase activities were evaluated in brain; however, the TAC and TOS levels have not been investigated. Our findings are consistent with these reports in terms of MDA levels as, in both studies, irisin had declines in MDA concentrations in brain and plasma.

In conclusion, the present study suggests a beneficial role of irisin on the synaptic plasticity in rat DG in vivo, as measured by LTP. Moreover, reduction of oxidative stress markers such as MDA by irisin may have shown that irisin exerted its effects by contributing to this myokine's antioxidant capacity.

In order to discover and verify how irisin potentiates synaptic plasticity in rats, further studies (i.e. genetic and/or molecular research) will be necessary.

\section{References}

1. Zarei M, Mohammadi S, Jabbari S, Shahidi S. Intracerebroventricular microinjection of kaempferol on memory retention of passive avoidance learning in rats: involvement of cholinergic mechanism(s). Int J Neurosci. 2019 Dec;129(12): 1203-12. https://doi.org/10.1080/00207454.2019.1653867

2. Farmer J, Zhao X, van Praag H, Wodtke K, Gage FH, Christie BR. Effects of voluntary exercise on synaptic plasticity and gene expression in the dentate gyrus of adult male Sprague-Dawley rats in vivo. Neuroscience. 2004;124(1):71-9. https://doi.org/10.1016/j.neuroscience.2003.09.029

3. Chen K, Zheng Y, Wei J-a, Ouyang H, Huang X, Zhang $F$, et al. Exercise training improves motor skill learning via selective activation of mTOR. Sci Adv. 2019 Jul;5(7):eaaw1888. https://doi.org/10.1126/sciadv.aaw1888

4. Mohammadi S, Oryan S, Komaki A, Eidi A, Zarei M. Effects of hippocampal microinjection of irisin, an exercise-induced myokine, on spatial and passive avoidance learning and memory in male rats. Int J Pept Res Ther. 2019 Mar;1-11. https://doi.org/10.1007/s10989-019-09842-2

5. Pedersen BK, Fischer CP. Beneficial health effects of exercise: the role of IL-6 as a myokine. Trends Pharmacol Sci. 2007 Apr;28(4):152-6. https://doi.org/10.1016/j.tips.2007.02.002

6. Boström P, Wu J, Jedrychowski MP, Korde A, Ye L, Lo JC, et al. A PGC1- $\alpha$-dependent myokine that drives brown-fat-like development of white fat and thermogenesis. Nature. 2012 Jan;481(7382):463-8. https://doi.org/10.1038/nature10777

7. Wrann CD, White JP, Salogiannnis J, Laznik-Bogoslavski D, Wu $J$, Ma D, et al. Exercise induces hippocampal BDNF through a PGC-1 $\alpha /$ FNDC5 pathway. Cell Metab. 2013 Nov;18(5):649-59. https://doi.org/10.1016/j.cmet.2013.09.008

8. Vaynman S, Ying Z, Gomez-Pinilla F. Hippocampal BDNF mediates the efficacy of exercise on synaptic plasticity and cognition. Eur J Neurosci. 2004 Nov;20(10):2580-90. https://doi.org/10.1111/j.1460-9568.2004.03720.x 
9. Askari H, Rajani SF, Poorebrahim M, Haghi-Aminjan $\mathrm{H}$, Raeis-Abdollahi E, Abdollahi M. A glance at the therapeutic potential of irisin against diseases involving inflammation, oxidative stress, and apoptosis: an introductory review. Pharmacol Res. 2018 Mar;129:44-55. https://doi.org/10.1016/j.phrs.2018.01.012

10. Tönnies E, Trushina E. Oxidative stress, synaptic dysfunction, and Alzheimer's disease. J Alzheimers Dis. 2017;57(4):1105-21. https://doi.org/10.3233/JAD-161088

11. Kelly DP. Medicine. Irisin, light my fire. Science. 2012 Apr;336(6077):42-3. https://doi.org/10.1126/science.1221688

12. Wu A, Ying Z, Gomez-Pinilla F. The interplay between oxidative stress and brain-derived neurotrophic factor modulates the outcome of a saturated fat diet on synaptic plasticity and cognition. Eur J Neurosci. 2004 Apr;19(7):1699-707. https://doi.org/10.1111/j.1460-9568.2004.03246.x

13. Mohammadi S, Golshani Y. Neuroprotective effects of rhamnazin as a flavonoid on chronic stress-induced cognitive impairment. J Adv Neurosci Res. 2017;4(2):30-7. https://doi.org/10.15379/2409-3564.2017.04.02.03

14. Paxinos $\mathrm{G}$, Watson $\mathrm{C}$. The rat brain in stereotaxic coordinates in stereotaxic coordinates. New York: Elsevier; 2007.

15. Shahidi S, Komaki A, Sadeghian R, Soleimani Asl S. Effect of a 5-HT1D receptor agonist on the reinstatement phase of the conditioned place preference test and hippocampal long-term potentiation in methamphetamine-treated rats. Brain Res. 2018 Nov;1698:151-60. https://doi.org/10.1016/j.brainres.2018.07.030

16. Lefèvre G, Beljean-Leymarie M, Beyerle F, Bonnefont-Rousselot D, Cristol JP, Thérond P, et al. [Evaluation of lipid peroxidation by measuring thiobarbituric acid reactive substances]. Ann Biol Clin (Paris). 1998 May-Jun;56(3):305-19. French.

17. Benzie IF, Strain JJ. The ferric reducing ability of plasma (FRAP) as a measure of "antioxidant power": the FRAP assay. Anal Biochem. 1996 Jul;239(1):70-6. https://doi.org/10.1006/abio.1996.0292

18. Erel O.A new automated colorimetric method for measuring total oxidant status. Clin Biochem. 2005 Dec;38(12):1103-11. https://doi.org/10.1016/j.clinbiochem.2005.08.008

19. Lourenco MV, Frozza RL, de Freitas GB, Zhang H, Kincheski GC, Ribeiro FC, et al. Exercise-linked FNDC5/irisin rescues synaptic plasticity and memory defects in Alzheimer's models. Nat Med. 2019 Jan;25(1):165-75. https://doi.org/10.1038/s41591-018-0275-4

20. Kramár EA, Chen LY, Lauterborn JC, Simmons DA, Gall CM, Lynch G. BDNF upregulation rescues synaptic plasticity in middle-aged ovariectomized rats. Neurobiol Aging. 2012 Apr;33(4):708-19. https://doi.org/10.1016/j.neurobiolaging.2010.06.008
21. Gulyaeva NV, Kudryashov IE, Kudryashova IV. Caspase activity is essential for long-term potentiation.J Neurosci Res. 2003 Sep;73(6):853-64. https://doi.org/10.1002/jnr.10730

22. Cheng A, Wan R, Yang JL, Kamimura N, Son TG, Ouyang X, et al. Involvement of PGC-1 $\alpha$ in the formation and maintenance of neuronal dendritic spines. Nat Commun. 2012;3(1):1250. https://doi.org/10.1038/ncomms2238

23. Daumas S, Hunter CJ, Mistry RB, Morè L, Privitera L, Cooper $\mathrm{DD}$, et al. The kinase function of MSK1 regulates BDNF signaling to CREB and basal synaptic transmission, but is not required for hippocampal long-term potentiation or spatial memory. eNeuro 2017 Feb;4(1): pii: ENEURO.0212-16.2017. https://doi.org/10.1523/ENEURO.0212-16.2017

24. Bailey $\mathrm{CH}$, Kandel ER, Si K. The persistence of long-term memory: a molecular approach to self-sustaining changes in learning-induced synaptic growth. Neuron. 2004 Sep;44(1):49-57. https://doi.org/10.1016/j.neuron.2004.09.017

25. Panahi Y, Rajaee SM, Johnston TP, Sahebkar A. Neuroprotective effects of antioxidants in the management of neurodegenerative disorders: A literature review. J Cell Biochem. 2019 Mar;120(3):2742-8. https://doi.org/10.1002/jcb.26536

26. Viggiano A, Viggiano E, Monda M, Viggiano A, Ascione S, Amaro $S$, et al. Intracerebroventricular injection of oxidant and antioxidant molecules affects long-term potentiation in urethane anaesthetized rats. Physiol Res. 2008;57(2):269-73.

27. Schrag M, Mueller C, Zabel M, Crofton A, Kirsch WM, Ghribi O, et al. Oxidative stress in blood in Alzheimer's disease and mild cognitive impairment: a meta-analysis. Neurobiol Dis. 2013 Nov;59:100-10. https://doi.org/10.1016/j.nbd.2013.07.005

28. Rinaldi P, Polidori MC, Metastasio A, Mariani E, Mattioli $P$, Cherubini A, et al. Plasma antioxidants are similarly depleted in mild cognitive impairment and in Alzheimer's disease. Neurobiol Aging. 2003 Nov;24(7):915-9. https://doi.org/10.1016/s0197-4580(03)00031-9

29. Behl C. Oxidative stress in Alzheimer's disease: implications for prevention and therapy. In: Behl C. Alzheimer's disease. Boston: Springer; 2005. p. 65-78. https://doi.org/10.1007/0-387-23226-5_3

30. O'Donnell E, Vereker E, Lynch MA. Age-related impairment in LTP is accompanied by enhanced activity of stress-activated protein kinases: analysis of underlying mechanisms. Eur J Neurosci. 2000 Jan;12(1):345-52. https://doi.org/10.1046/j.1460-9568.2000.00900.x

31. Barrera G, Pizzimenti S, Daga M, Dianzani C, Arcaro A, Cetrangolo GP, et al. Lipid peroxidation-derived aldehydes, 4-hydroxynonenal and malondialdehyde in aging-related disorders. Antioxidants. 2018 Jul;7(8):102. https://doi.org/10.3390/antiox7080102 